\section{VETERINARY SCIENCE}

\section{Effect of High-level Copper on the Depot Fat of Bacon Pigs}

THE supplementation of feed for fattening pigs with copper in the form of $\mathrm{CuSO}_{4}, \mathrm{CuO}$ and $\mathrm{CuS}$ has been shown by several workers to improve the rate of gain and feed conversion ${ }^{1-9}$. Our main interest has been in the determination of the quality and properties of depot fat and the level of copper in the livers of pigs fed high-level copper.

Three rations were compared: (1) basal; (2) basal plus citric acid (1 per cent); (3) basal plus $\mathrm{CuSO}_{4}(250$ p.p.m. copper).

Swedish Landrace pigs were allotted at random to treatments on the basis of litter outcome groups and balanced for sex and initial weight within treatments.

The feeding wais $a d l i b$. from self-feed hoppers with unrestricted water. The basal rations were of standard formulation fed from $20-90 \mathrm{~kg}$.

Growth rate and feed consumption were recorded as well as the usual carcass measurements at slaughter according to the Swedish progeny-testing system. In addition, the following determinations were made on the samples of backfat: Iodine number according to the Hanus method; consistency measured by a method developed at this Institute. A 1-ml. sample of liquidrendered fat was introduced, by means of a syringe, into a glass tube, $8 \mathrm{~cm}$ long and $6 \mathrm{~mm}$ inner diameter, which was ground on the inside. The tubes were held upright in a rack with the bottom end dipping into mercury contained in a glass tray. The liquid fat builds a plug at the level of the mercury. After solidifying the fat is kept for 6 days at a constant temperature of $20^{\circ} \mathrm{C}$. By means of a manometer the amount of vacuum required to extract the fat from the tubes is measured.

Oxidative rancidity ('keepability' at $55^{\circ} \mathrm{C}$ ) was measured by daily determination of the peroxide number by the Lea method to fix the point at which oxidation begins.

The fat samples used for the foregoing determinations were obtained by removing a 1 -in. wide strip of backfat down to the longissimus dorsi muscle from between the neck and the tail. The strip of fat was then sampled, rendered and filtered.

The amount of copper in the liver and longissimus dorsi muscle was determined by the carbamate method.

Analysis of variance revealed that there was no significant difference between the citric acid and control treatments for any of the depot-fat factors examined. The results for these two treatments were therefore pooled and tested against the copper treatment.

The more important results are presented in Table 1.

Of particular interest was the highly significant difference in iodine number of the backfat between copper-fed pigs and controls.

The measurement of consistency also revealed a highly significant difference between copper and controls, showing

Table 1. Results of IODINE NUMBER, CONSISTENCY AND 'KEePaBintTy'

$$
\begin{aligned}
& \text { OF DEPOT FAT AND THE COPPFR CONTENT (P.P.M.) OF LIVERS }
\end{aligned}
$$

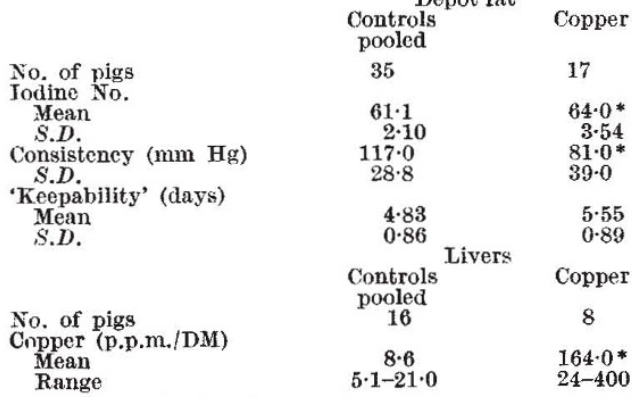

* Significant at the 1 per cent level. that much less vacuum was required to extract the fat in the case of copper-fed pigs compared with the controls. This result is an indication that a softer backfat results from the feeding of copper additives and is in agreement with the iodine values.

Rather surprisingly there was no clear difference in the 'keepability' of the fat between the copper-fed pigs and controls. In view of the difference in iodine number and consistency values the result for 'keepability' calls for some explanation but, as this was a preliminary experiment, the copper content of the fat was not determined and further research is planned to elucidate this somewhat contradictory result.

The level of copper in the livers has clearly been influenced by dietary copper, but the variation within the copper-treated pigs was oxtremely wide, ranging from 24 p.p.m. to 400 p.p.m. copper which is of the same order reported by Barber ${ }^{2}$. The variation within the control pigs was much less. There was no difference in the level of copper in the longissimus dorsi muscle between treat. ments, all values falling within the range $0 \cdot 3-0 \cdot 6$ p.p.m. copper.

The average backfat thickness was not influenced significantly by treatment: the mean for copper was 31.0 $\mathrm{mm}$ and for controls $32.0 \mathrm{~mm}$. As the backfat thickness is known to be highly correlated with the iodine number, an analysis of covariance was carried out with backfat as the independent variable. The adjusted iodine number mean differences were still highly significant, but the mean difference decreased from $2 \cdot 9$ unadjusted (compare with Table 1) to $2 \cdot 6$ for the adjusted iodine number means.

A possible explanation of the results obtained for fat properties may be that high levels of dietary copper influence the absorption of dietary fat and also influence the transport of depot fat which has resulted in the deviation from the normal composition of depot fat. It is also possible that the high levels of copper found in the livers interfere with the normal liver functions with respect to fat metabolism.

\section{Michael Taylor} SigVARD Thomke

Department of Animal Husbandry,

Agricultural College of Sweden, Uppsala 7.

${ }^{1}$ Barber, R. S., et al., Chem. and Indust., 48, 1554 (1955).

${ }^{2}$ Barber, R. S., et al., Brit. J. Nutr., 11, 70 (1957).

${ }^{3}$ Barber, R. S., et al., Anim. Prod., 2, 105 (1960).

4 Barber, R. S., et al., Brit. J. Nutr., 15, 189 (1961).

${ }^{5}$ Hawbaker, J. A., et al., J. Anim. Sci, 20, 163 (1961).

- Lucas, I. A. M., et al., Anim. Prod., 3, 11 (1961).

' Bowler, R. J., et al., Brit. J. Nutr., 9, 358 (1935).

${ }^{8}$ Bunch, R. J., et al., J. Anim. Sci., 20, 723 (1961).

${ }^{9}$ Fagan, V. J., et al., J. Agric. Sci., 56, 161 (1961).

\section{PSYCHIATRY}

\section{Psychiatrist as a Variable in the Process of Interview and Treatment}

THE doctor-patient relationship is fundamental to the practice of medicine and psychotherapy. The psychiatrist's attitudes and feelings in the interview were examined in an experimental design at the Lafayette Clinic, a psychiatric training and research centre. A Likert-type questionnaire with 39 items which explored the conscious subjective reactions of the therapist to the patient was utilized with 16 resident physicians immediately following each doctor's initial psychiatric interview on 19 consecutive and random patients.

A factor analysis of the data on 300 patients showed eight factors: communication-ego strength, therapist discomfort, patient dependency and acceptance of the therapist, patient aggression and acting out, physical attractiveness, acceptability for treatment, patienttherapist similarity, and therapist liking of the patient. 